\title{
Dietrich Fischer Dieskau (1925-2012)
}

Con Dietrich Fischer Dieskau, sin duda se ha ido uno de los cantantes y músicos más importantes de nuestra época. Fischer Dieskau era un barítono que descollaba tanto en la interpretación de ópera, Lied alemán, oratorio y música contemporánea.

Su gran especialidad era el Lied. En ese rubro desarrolló una labor inmensa. Grabó -y por supuesto cantó- obras de Schubert, Schumann, Mozart, Brahms, Mahler, Wolf, Strauss, Loewe y otros. Tenía en su repertorio 3000 canciones. Grabó, junto al pianista Gerald Moore, prácticamente todos los Lieder de Schubert para voz masculina. Sus grandes ciclos los grabó más de una vez.

Cantó y grabó los roles protagónicos de óperas de Mozart, Verdi, Wagner y otros compositores. Sus personificaciones en roles como Don Giovanni o Conde Almaviva (Bodas de Figaro) eran tan profundas y originales como sus interpretaciones de Lied, en lo musical como en lo actoral. Tanto su debut como su despedida como cantante de ópera fueron obras de Verdi. Su primer rol fue Posa, en la ópera Don Carlos, y su última aparición fue Falstaff en la ópera homónima de este compositor italiano.

Fischer Dieskau era además director de orquesta y musicólogo. Sus profundas investigaciones tuvieron como resultado libros de gran interés sobre Schubert y sus canciones, los que contienen una cuidadosa orientación para la comprensión e interpretación de las canciones.

En una entrevista, Dietrich Fischer Dieskau dijo, refiriéndose a las canciones de Schubert: “... están llenas de color y posibilidades: giras en torno a ellas y te aproximas al centro, pero nunca lo alcanzas. Schubert proporciona la perfecta unión de texto y música".

En todos los géneros de canto abordados por Fischer Dieskau, su característica interpretativa es una gran originalidad, respetando siempre lo escrito por el compositor, pero realzando hasta los más pequeños detalles para lograr así una expresión plena.

Fischer Dieskau comenzó a cantar a fines de los años 40 y comienzo de los 50 del siglo pasado. En esa época se enseñaba y practicaba una interpretación muy austera, especialmente del Lied alemán. Y él abrió una puerta: sin salirse nunca del estilo ni del respeto por la partitura, encontró detalles expresivos en el texto y en la música y los proyectó con gran convicción y arte, para darle una nueva vida al género.

Fue, en fin, un gran artista, un gran intelectual, que con su labor enriqueció en gran forma la vida musical del siglo XX.

Hanns Stein

Facultad de Artes, Universidad de Chile hsteink@ctcinternet.cl 